\title{
A CRIANÇA COM DEFICIÊNCIA VISUAL: UMA CONTRIBUIÇÃO A PARTIR DO DESENVOLVIMENTO DO PROJETO DE BRINQUEDOS
}

\section{THE VISSUALLY IMPAIRED CHILD: A CONTRIBUTION FROM THE DEVELOPMENT OF TOY DESIGN}

\author{
Christian Cambruzzi da Silva ${ }^{1}$, Graduando \\ Fabrício Reguelin Auler ${ }^{2}$, Graduando \\ Roseane Santos da Silva ${ }^{3}$, M. Sc. \\ (1) UFSM, e-mail: christiancambruzzi@gmail.com \\ (2) UFSM, e-mail: fabricio.reguelin@gmail.com \\ (3) UFSM, e-mail: roseanedoro@yahoo.com.br
}

Brinquedos, Deficiência Visual, Projeto de Produto

\begin{abstract}
O presente artigo tem como objetivo relatar o processo de desenvolvimento de dois brinquedos com configurações voltadas ao uso da criança com deficiência visual. Pode-se dizer que ainda são poucas as referências sobre design de brinquedos para crianças com deficiência, assim, a contribuição deste trabalho está na aplicação de conhecimento do design no desenvolvimento de brinquedos inclusivos. A metodologia utilizada foi embasada em métodos de desenvolvimento de projeto de produtos previstos em Bonsiepe (1987), Baxter (2000) e Löbach (2001). Foram desenvolvidos dois brinquedos em fases distintas por estudantes do curso de Desenho Industrial da Universidade Federal de Santa Maria. Os resultados principais dos testes apontaram para possíveis melhorias nos brinquedos desenvolvidos evidenciando a importância do usuário em fazer parte do processo de desenvolvimento dos produtos.
\end{abstract}

\section{Toys, Visual impairment, Product Design}

This article aims to report the development process of two toys with configurations aimed at the use of the visually impaired child. It can be said that there are still few references about toy design for children with disabilities, so the contribution of this work is in the application of design knowledge in the development of inclusive toys. The methodology used was based on methods of product design development foreseen in Baxter (2001), Bonsiepe (1987) and Löbach (2001). Two toys were developed in different phases by students of the Industrial Design course. The main results of the tests pointed to possible improvements in the developed toys, highlighting the importance of the user being part of the product development process. 


\section{$16^{\circ}$ \\ ERGODESIGN USIHC CINAHPA}

$16^{\circ}$ Ergodesign - Congresso Internacional de Ergonomia e Usabilidade de Interfaces Humano Tecnológica: Produto, Informações Ambientes Construídos e Transporte

$16^{\circ}$ USIHC - Congresso Internacional de Ergonomia e Usabilidade de Interfaces Humano Computador

CINAHPA | 2017 - Congresso Internacional de Ambientes Hipermídia para Aprendizagem.

\section{Introdução}

O brinquedo é um importante artefato utilizado na fase da infância. Através dele a criança tem a possibilidade de ter suas potencialidades de aprendizagem aumentadas por meio de características formais que estimulam e propiciam a linguagem lúdica pertinente nesse período da vida. No caso da criança com deficiência visual não é diferente. Além das atribuições inerentes ao brinquedo comuns a qualquer criança, este produto pode ser fonte de estímulo aos sentidos remanescentes e/ou aos resquícios visuais.

O presente artigo aborda sobre o desenvolvimento de dois brinquedos que foram projetados tendo em vista o público alvo de crianças com deficiência visual. O objetivo principal desse trabalho é mostrar a importância do esforço projetual na configuração de brinquedos adequados, visando aplicação para o público específico.

\section{Revisão de Literatura}

\subsection{A criança com deficiência visual}

Ao termo deficiência visual, pode-se entender dois principais tipos de acometimentos ao sentido da visão: a cegueira e a baixa visão (ou visão subnormal). Nesses termos, destacam-se as delimitações de acordo com o decreto $\mathrm{n}^{\circ} 3.298$, de 20 de dezembro de 1999:

"Art. $3^{\circ}$ Para os efeitos deste decreto, considera-se: I - deficiência - toda perda ou anormalidade de uma estrutura ou função psicológica, fisiológica ou anatômica que gere incapacidade para o desempenho de atividade, dentro do padrão considerado normal para $o$ ser humano;II - deficiência permanente aquela que ocorreu ou se estabilizou durante um período de tempo suficiente para não permitir recuperação ou ter probabilidade de que se altere, apesar de novos tratamentos; e III - incapacidade - uma redução efetiva e acentuada da capacidade de integração social, com necessidade de equipamentos, adaptações, meios ou recursos especiais para que a pessoa portadora de deficiência possa receber ou transmitir informações necessárias ao seu bem-estar pessoal e ao desempenho de função ou atividade a ser exercida."

[BRASIL, 1999, Art. 3º]

Esse mesmo decreto dispõe sobre as especificações em relação ao termo cegueira que seria "na qual a acuidade visual é igual ou menor que 0,05 no melhor olho, com a melhor correção óptica;" [BRASIL, 1999, Art. $4^{\circ}$ ]. E, também, sobre a baixa visão "que significa acuidade visual entre 0,3 e 0,05 no melhor olho, com a melhor correção óptica [Ex.:BRASIL, 1999, ART. $4^{\circ}$ ].

Assim, a cegueira seria o caso mais avançado da deficiência visual, impossibilitando a visão de qualquer tipo de informação clara e possível de ser interpretada pelo campo visual, mesmo com a utilização de óculos ou lupas. A realização de atividades do individuo com cegueira são alicerçadas nos demais sentidos intitulados sentidos remanescentes.

Já com a baixa visão, o indivíduo tem a diminuição da acuidade visual, com turvação, nublação ou perda de partes do campo visual. Como uma parte da visão ainda é possível de ser utilizada, além do apoio nos sentidos remanescentes, os chamados resquícios visuais.

No caso de crianças com cegueira, destaca-se, o trabalho do sentido tátil. O reconhecimento visual passa a ser re-significado através do tato, tendo a possibilidade de aproximar a realidade dos objetos, através das diferentes superfícies, formas e pesos. Unido a isso, o tato deve ser estimulado antecipando a alfabetização do sistema Braille, onde a leitura de números e letras é realizada com as mãos. Quanto mais a criança com deficiência visual é educada a tocar, escutar, explorar seus demais sentidos e ver com as mãos, menos a falta da visão prejudicará seu desenvolvimento. [DIAS, 1995; GIL, 2000].

Para a criança com baixa visão, padrões de estampas e diferentes intensidades de cores podem
Realização:

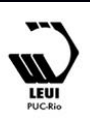




\section{$16^{\circ}$ \\ ERGODESIGN USIHC CINAHPA}

ser administrados através de objetos a fim de que se possa tentar mensurar a intensidade da perda visual [PEREIRA, 2009]. A luminosidade e a refletância das superfícies são características que também devem ser consideradas na interação com crianças baixa visão. Em alguns casos, a luminosidade auxilia na melhor visão, esses indivíduos geralmente necessitam de auxílio de um ponto de luz bem próximo dos objetos, para compreenderem as informações visuais. Por outro lado, alguns casos apresentam aversão (Photofobia) e, portanto devem ser protegidos de luz muito intensa. Para isso também a característica da refletância de alguns materiais que pode incomodar, trazendo prejuízos para concentração da criança [WENZEL, et al. 2006].

Preisler [1997] relata que crianças com deficiência visual encontram dificuldades em se envolver em atividades de brincadeira livre com crianças videntes e se limitam a interagir com o adulto ou a brincar sozinhas. Segundo a autora, isso se dá principalmente devido à pouca disponibilidade de brinquedos interessantes para as crianças cegas, já que na maioria deles predominam atrativos visuais, e ao fato de que, na brincadeira livre, as crianças videntes interagem predominantemente por meios não verbais, como expressões faciais e movimentos corporais, que dificultam a participação da criança cega.

Nesse sentido, o favorecimento da interação entre parceiros pode contribuir para os processos de construção e transformação de significados, no desenvolvimento da criança com necessidades especificas. Portanto entende-se que o brinquedo pode desempenhar importante papel no sentido de proporcionar estímulos e específicos e gerar maior integração social entre crianças com e sem deficiências visuais.

\section{Metodologia}

A metodologia do presente trabalho deu-se a partir de fases pertinentes ao que tange às metodologias de desenvolvimento de projeto de produtos. Para tanto, levou-se em consideração as principais fases metodológicas de Löbach [2001], bem como analises especificas prescritas em Baxter [2000] e $16^{\circ}$ Ergodesign - Congresso Internacional de Ergonomia e Usabilidade de Interfaces Humano Tecnológica: Produto, Informações Ambientes Construídos e Transporte

$16^{\circ}$ USIHC - Congresso Internacional de Ergonomia e Usabilidade de Interfaces Humano Computador

CINAHPA | 2017 - Congresso Internacional de Ambientes Hipermídia para Aprendizagem.

\section{Desenvolvimento}

A seguir descreve-se as etapas realizadas no desenvolvimento dos dois brinquedos. Cada um deles foram realizados por um aluno do curso de Desenho Industrial e portanto com aplicação de analises que os mesmos julgaram ser pertinentes.

\subsection{Brinquedo 1 - Ástromus}

\subsubsection{Fase I}

Deu-se enfoque a crianças com baixa visão, cuja faixa etária vai dos 2 a 6 anos de idade. O brinquedo deveria, ainda, oferecer estímulos para um desenvolvimento saudável da criança.

No estudo de morfologia e tipos de encaixe dos brinquedos, elaborou-se um painel semântico contendo imagens de diversos brinquedos de encaixe, assim como algumas luminárias infantis.

A partir dos resultados obtidos por meio das análises anteriores, uma lista de requisitos, que permite avaliar e hierarquizar quais fatores devem receber prioridade, foi preparada para selecionar variáveis que permitam solucionar os problemas do projeto.

\subsubsection{Fase II}

Nessa etapa, delimitaram-se algumas temáticas, relacionadas com elementos bastante presentes na infância: animais, aventura ou espaço sideral. A seleção de ilustrações conforme pode ser visto na exibe as cinco alternativas filtradas por coerência com a proposta, com funcionamento por encaixe ou peças giratórias.

\subsubsection{Fase III}

Após escolha da alternativa, nessa etapa realizouse um desenho definitivo a concepção de modelos virtuais e tridimensionais, assim como uma noção dos possíveis materiais e acabamento.

A geometrização do brinquedo, definido como sendo um foguete, permite alcançar uma harmonia 


\section{$16^{\circ}$ \\ ERGODESIGN USIHC CINAHPA}

entre as partes e coerência nas formas, como se vê na Figura 1.

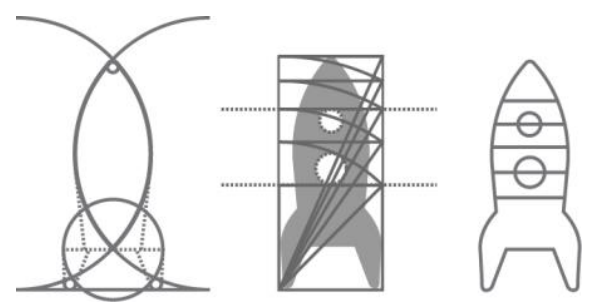

Fig. 01 Geometrização e proporção da forma final (retângulo raiz de 5). Fonte: Autor.

Um estudo de cores contribuiu para a escolha de cores contrastantes para as peças do brinquedo.

Por fim, com uma estética e conceito já definidos, como se vê na Figura 2. O brinquedo é composto por trinta e duas peças, divididas em oito grupos com quatro formatos distintos, porém, simplificados, com diferentes texturas, que se encaixam em uma estrutura em formato de foguete, o qual possui iluminação interna, colorindo o ambiente.

As peças que compõem o foguete, quando encaixadas em seu devido lugar, formam janelas, as quais permitem a passagem mais intensa da iluminação. A opção temática 'foguete' foi escolhida como símbolo de exploração, além de ser um objeto bastante atrativo para as crianças da faixa etária em questão.

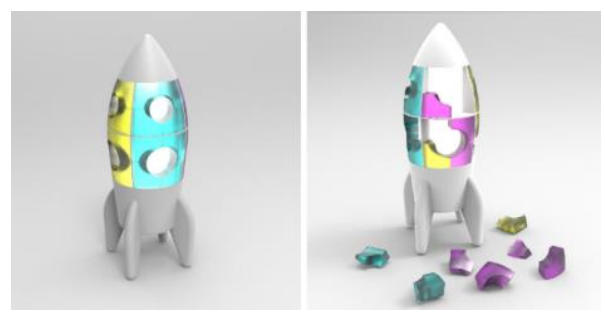

Fig. 02 Renderização final do brinquedo simulando possível disposição das peças. Fonte: Autor.

\subsubsection{Fase IIV}

Nessa fase delimitou-se configurações para elaboração de um protótipo funcional do brinquedo.

O material mais acessível e com as características $16^{\circ}$ Ergodesign - Congresso Internacional de Ergonomia e Usabilidade de Interfaces Humano Tecnológica: Produto, Informações Ambientes Construídos e Transporte

$16^{\circ}$ USIHC - Congresso Internacional de Ergonomia e Usabilidade de Interfaces Humano Computador

CINAHPA | 2017 - Congresso Internacional de Ambientes Hipermídia para Aprendizagem.

mais próximas de se obter a translucidez das peças encaixáveis utilizado foi o isopor, com estrutura em madeira e componentes elétricos [figura 3].

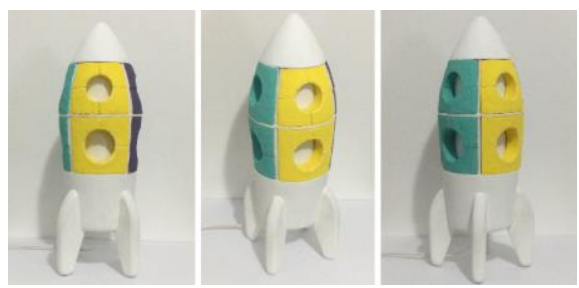

Fig. 03 Protótipo. Fonte Autor.

\subsection{Brinquedo 2 - Artur}

\subsubsection{Fase I}

A proposta para este brinquedo era $\mathrm{o}$ desenvolvimento de um quebra-cabeça tridimensional de madeira para crianças com cegueira, na idade acima de 7 anos.

A análise de configuração contribuiu para extrair elementos aproveitáveis para determinar encaixes do quebra-cabeça, servindo como instrumento para estabelecer alguns detalhes formais do brinquedo.

Nos requerimentos de uso, foi definido que a peças deveriam apresentar desenhos regulares, para não haver mal posicionamento do encaixe, além de apresentar facilidade na manipulação. Nos requerimentos de função, o brinquedo apresentaria versatilidade que deveria variar entre a função de encaixe e desencaixe, apresentando resistência aos esforços que o usuário faria durante os encaixes; o acabamento seria com tintas com cores vibrantes.

\subsubsection{Fase II}

Na segunda fase do projeto, aconteceu a Geração de Alternativas com a produção das ideias baseadas na associação das análises e requerimentos anteriores. Foram apresentadas mais de 20 alternativas, variando entre formas abstratas e figurativas. Uma ferramenta utilizada para a produção das alternativas foi o painel semântico, composto de imagens de brinquedos e ursos. A partir da avaliação das alternativas, foi definido o desenho. [Figura 04]
Realização:
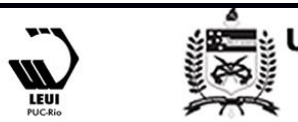


\section{$16^{\circ}$ \\ ERGODESIGN USIHC CINAHPA}
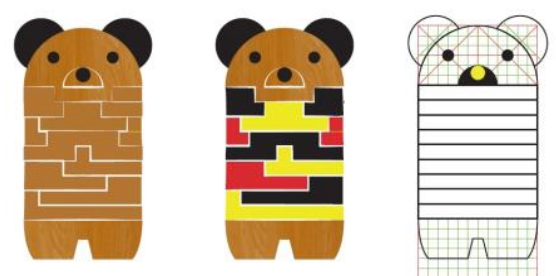

Fig. 04 Desenho definitivo e proporção aplicada na cabeça e na base do brinquedo. Fonte: Autor.

\subsubsection{Fase III}

A fase de teste com o mocape foi fundamental para realizar mais alterações, principalmente o desenho dos encaixes das peças.

Apesar da geração do brinquedo ter como usuário norteador a criança com deficiência visual, um teste de cores foi necessário, pensando na produção de um brinquedo universal, para que crianças com e sem deficiência pudessem interagir durante $o$ ato de brincar.

Em seguida realizou-se a elaboração de uma modelagem em software tridimensional virtual e avaliou-se as cores escolhidas conforme pode ser visualizado na Figura 5.

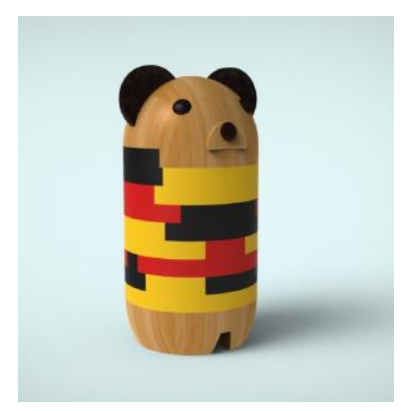

Fig. 05 Modelagem tridimensional do brinquedo, com aplicação de cores. Fonte: Autor.

\subsubsection{Fase IV}

Para confecção do protótipo [Figura 06], utilizouse madeira pinus para todas as peças do brinquedo. A madeira foi lixada, procurando torna-la mais lisa para aplicação da tinta e do verniz. O selador e o verniz foram utilizados para dar acabamento para a cabeça e a base do brinquedo, estas peças não foram pintadas, valorizando as cores e texturas da madeira pinus. $16^{\circ}$ Ergodesign - Congresso Internacional de Ergonomia e Usabilidade de Interfaces Humano Tecnológica: Produto, Informações Ambientes Construídos e Transporte

$16^{\circ}$ USIHC - Congresso Internacional de Ergonomia e Usabilidade de Interfaces Humano Computador

CINAHPA | 2017 - Congresso Internacional de Ambientes Hipermídia para Aprendizagem.

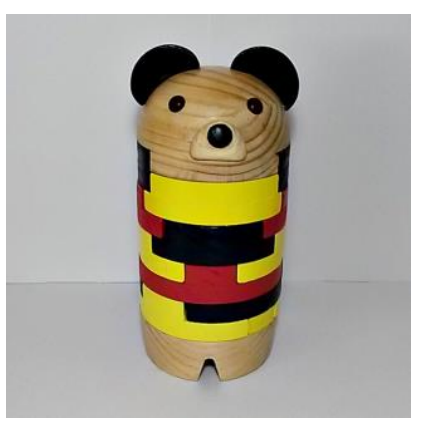

Fig. 06 Protótipo do projeto Artur: Quebra-cabeça tridimensional, feito em madeira pinus e acabamento com selador, verniz e tinta acrílica.

\section{Resultados}

\subsection{Teste de Uso}

Os testes foram desenvolvidos de maneira sistemática em parceria com a Associação de Cegos e Deficientes Visuais da cidade de Santa Maria-RS.

\subsubsection{Teste Brinquedo 1-Ástromus}

No teste com usuários do brinquedo Ástromus, as crianças com baixa visão demonstraram interesse na montagem das peças e nas diferentes possibilidades de confecção a partir das variadas cores. Com um tempo aproximado de 25 minutos de interação com o brinquedo, as crianças conseguiram entender seu funcionamento, no entanto, com certa dificuldade para encaixar algumas peças. $\mathrm{O}$ formato de foguete do brinquedo, aliado às diferentes cores, atraiu bastante a atenção das crianças. Como possível melhoria, pode-se citar a diminuição do número de peças, o que facilitaria a montagem e diminuiria o número de encaixes.

\subsubsection{Teste Brinquedo 2-Artur}

Durante o teste do brinquedo Artur, as crianças com deficiência visual demonstram interesse no brinquedo, apresentando curiosidade durante a montagem do quebra-cabeças. Podemos citar a dificuldade em alguns encaixes, onde algumas crianças invertiam a peça. Apesar dessa dificuldade, conseguiram compreender a lógica do jogo e conseguiam montar em um tempo com 


\section{$16^{\circ}$ \\ ERGODESIGN USIHC CINAHPA}

média aproximada de 8 minutos. Entre algumas sugestões após o teste com os usuários, podemos citar alterações no formato de algumas peças e aplicação de texturas para a criança poder fazer associação.

\section{Considerações Finais}

Estabelecer uma conexão completa, com o uso inteligente e inclusão social, é um fator importante para elevar a necessidade do usuário a um novo patamar de importância. Estar atento ao desenvolvimento tecnológico e cultural das massas estará cada vez mais em evidência, assim como estar ciente do que a sociedade busca e como suprir suas necessidades com mecanismos de inclusão e convivência, atuando como agente de interação social.

Para melhor avaliação e verificação da solução final de um brinquedo, é essencial que se elaborem testes que permitam uma maior consistência e que atenda às necessidades. Entende-se que dois foram os principais resultados desse trabalho. $\mathrm{O}$ primeiro diz respeito ao esforço projetual empregado e a importância do envolvimento do aluno em experiências projetuais reais. $\mathrm{O}$ segundo diz relação ao estudo continuo sobre necessidades do público em questão do presente artigo que é o de criança com deficiência visual tendo em vista uma perspectiva de inclusão com demais crianças.

Assim, ressalta-se a necessidade de desenvolvimento de pesquisas nesse sentido a fim contribuir para a cultura de inclusão e desenvolvimento social.

\section{Referências Bibliográficas}

ALMEIDA, Ivany Lima. Aprendizagem e Desenvolvimento da Crianças Segundo as Teorias de Vygotsky. Disponível em

$<$ http://www.webartigos.com/artigos/aprendizagem -e-desenvolvimento-da-crianca-segundo-as-teoriasde-vygotsky/115495/> Acesso em 10 Out 2016.

BRASIL. Portal de ajudas técnicas para educação: equipamento e material pedagógico para educação, capacitação e recreação da $16^{\circ}$ Ergodesign - Congresso Internacional de Ergonomia e Usabilidade de Interfaces Humano Tecnológica: Produto, Informações Ambientes Construídos e Transporte

$16^{\circ}$ USIHC - Congresso Internacional de Ergonomia e Usabilidade de Interfaces Humano Computador

CINAHPA | 2017 - Congresso Internacional de Ambientes Hipermídia para Aprendizagem.

pessoa com deficiência física: recursos pedagógicos adaptados. Brasília: MEC, SEESP, 2002. Disponível em:

<http://portal.mec.gov.br/seesp/arquivos/pdf/rec_a daptados.pdf>. Acesso em: 1 nov. 2016.

BRASIL. Decreto n ${ }^{\circ} 3.298$, de 20 de Dezembro de 1999.

Inmetro. Brinquedos Aprendidos II. Disponível em:

<http://www.inmetro.gov.br/consumidor/produtos/ brinquedos2.asp> Acesso em 19 mar. 2017

LÖBACH, Bernd. Design industrial: bases para a configuração dos produtos industriais. 1. Reimp. São Paulo: Editora Blucher, 2007.

PEREIRA, M.L. D. Design inclusivo - um estudo de caso: tocar ver - crianças cegas e de baixa visão. 2009. Dissertação de Mestrado - Faculdade de Engenharia, Pós Graduação em Design e

Marketing, Universidade do Minho, Braga.

Disponível em:

<http://repositorium.sdum.uminho.pt/bitstream/182 2/10741/1/tese.pdf>. Acesso em: 1 nov. 2016.

PREISLER, G. (1997). Social and emotional development of blind children: A longitudinal study. In V. Lewis \& G. M. Collis (Eds.), Blindness and psychological development in young children (pp. 116-129). London: The British Psychological Society.

SÁ, M.(Org). Deficiência Visual. Brasília: MEC, Secretaria de Educação Especial, 2000.

WENZEL. Macular pigment optical density and photophobia light threshold. Vision Research.

Disponível em: <http://ac.els-

cdn.com/S0042698906004500/1-s2.0-

S0042698906004500-main.pdf?_tid=c4fdbc6e-

13e8-11e2-b588-

00000aab0f02\&acdnat=1349990303_e297d9941b 1c06c6bc46d5e51f3e17392006>. Acesso em: 1 nov. 2016. 